\title{
A IMIGRAÇÃO ESPANHOLA PARA O BRASIL E A FORMAÇÃO DA FORÇA-DE-TRABALHO NA ECONOMIA CAFEEIRA: $1880-1930^{1}$
}

\author{
José de Souza Martins ${ }^{2}$
}

RESUMO: Dentro de um prisma comparativo, o artigo analisa especificidades da imigração espanhola com relação à italiana, que veio em parte substituir depois de 1902 . Em sua maioria composta por camponeses, os espanhoes tambem foram arregimentados como mão de obra para as fazendas de café da Alta Mogiana e Paulista, chegando ao Brasil após 1905. Enquanto mão de obra pouco qualificada, encontraram menos oportunidades de ascenção social do que os italianos. Também sofreram o impacto da transiçâo do trabalho escravo, porém encontraram as condições do colona to já transformadas, com pagamentos em espécie. Poucos entretanto chegaram a possuir pequenas propriedades agrícolas. Foram em geral assimilados, deixando relativamente poucos traços de identidade cultural e comunitária.

UNITERMOS: camponeses, assalariados, imigração subvencionada, formação do mercado de trabalho livre.

\section{Uma imigração tardia}

Quando se fala na imigração estrangeira para o Brasil, entre as últimas décadas do século XIX e as primeiras do século XX, é comum conceber-se o imigrante como substituto do escravo e, em conseqüência, tratá-lo como categoria indiferençada. Supostamente, todos os imigrantes das várias nacionalidades assumiram, no contacto com a sociedade brasileira, as mesmas

1 Trabalho apresentado no Seminário sobre Los españoles en Iberoamerica en la época de la emigración masiva, organizado pelo Prof. Nicolás Sánchez-Albornoz e realizado na Universidad Internacional Menendez Pelayo. La Corufia, Espanha - 15 a 17 de julho de 1985.

2 Sociologia - FFLCH/USP. 
MARTINS, José de Souza. A imigração espanhola para o Brasil e a formação da força-de-trabalho na economia cafeeira: $1880-1930$.

caraterísticas sociais e culturais, diferençados unicamente pela língua de origem. $\mathrm{Na}$ verdade, atribui-se a todos os imigrantes um perfil que foi o do imigrante ialiano, supondo-se que os imigrantes das várias nacionalidades tiveram a mesma trajetória no Brasil.

Neste trabalho, pretendo desenvolver algumas idéias relacionadas com a constatação inicial de que essa suposição não é verdadeira. Imigrantes de diferentes nacionalidades tiveram no Brasil diferentes trajetórias. É provável que essa diferenciação esteja em parte relacionada com as características sociais e culturais de cada grupo, com as peculiaridades dos fatores de emigração. Procuro, no entanto, apanhar essas diferenças a partir de um outro ângulo de interpretação. Entendo que os modos diferenciados de absorção do imigrante na sociedade brasileira estáo, em grande parte, relacionados com as mudanças ocorridas nessa mesma sociedade ao longo do tempo. Em cada momento de um período como o que tomo por referência, 1880 a 1930, as circunstâncias e as condições de incorporação do imigrante foram diferentes. No limite, isso quer dizer que o imigrante de uma mesma nacionalidade encontrou situações distintas em diferentes momentos.

Essa perspectiva é fundamental, também, para entender porque há diferenças importantes, por exemplo, entre o imigrante espanhol e o imigrante italiano. A grande maioria dos imigrantes de cada uma dessas nacionalidades chegou ao Brasil em épocas e circunstâncias diversas, fato que marcou o destino de cada grupo e o modo como se integrou, ou não se integrou, na sociedade brasileira.

Justamente porque tem sido comum tratar os imigrantes de diferentes nacionalidades como se tivessem cumprido uma mesma e igual trajetória no Brasil é que, sempre que possível, farei comparações entre o imigrante espanhol e o imigrante italiano. Por meio do recurso comparativo, será possível mostrar as diferenças que há entre ambos, às vezes diferenças substantivas. É claro que o objetivo final do trabalho não é, exclusiva e principalmente, o de fazer uma discussão sobre o imigrante espanhol. Mas, através da diferença representada por ele e através da sua inserção peculiar na economia cafeeira de São Paulo, analisar alguns aspectos das relações de trabalho nas fazendas de café, suas transformações e sua crise. Em outras palavras, o objetivo é considerar a diferenciação da força de trabalho que, no período indicado, aparece escamoteada pela diferenciação de nacionalidade do trabalhador. A diferenciação do trabalhador rural pela nacionalidade de origem, como ocorreu 
no café, encobriu um fato de grande importância: com freqüência, $a$ diferenciação por nacionalidade do trabalhador esconde mudanças nas relações de trabalho, no próprio processo de trabalho e nas relações entre renda fundiária e acumulação de capital.

O ponto de partida é este: 0 imigrante espanhol não se defrontou, de modo geral, com as mesmas circuntâncias históricas e com as mesmas condições que o imigrante italiano havia encontrado. Ele se destinou a repor a força de trabalho do imigrante italiano, que não estava sendo recriada pela própria imigração italiana ou que estava abandonando o país desde fins do século XIX. A partir de 1905, a imigração espanhola para São Paulo passou a ser, durante certo tempo, a mais numerosa. Até então a imigração italiana havia sido mais importante numericamente ${ }^{3}$. O imigrante italiano estava retornando a seu país, reemigrando para a Argentina e o Uruguai ou se deslocando para as zonas pioneiras, onde se expandiam os cafezais. Em segundo lugar, o imigrante espanhol destinou-se, também, aos cafezais das novas zonas cafeeiras de São Paulo, que concorriam com os cafezais das zonas Mojiana e Paulista pela mão-de-obra. O fluxo de abastecimento dos cafezais com trabalhadores italianos havia sido interrompido, em 1902, com o decreto Prinetti, que proibira a imigração subvencionada para o Brasil ${ }^{4}$. Esses dois fatores se combinaram para que, em diferentes regiöes e de

A imigração espanhola predominou sobre a imigração italiana de 1905 a 1919, no Brasil, e de 1905 a 1920, em São Paulo. Foi exceção, em ambos os casos, o ano de 1907, em que predominou a imigração italiana sobre a espanhola. Cf. Boletim do Departamento Estadual do Trabalho. Säo Paulo: Typ. Brasil, Rothschild \& Cia., n. 12 e 13, p. 805 e ss, anno III, $3^{\circ} \mathrm{e} 4^{\circ}$ trim. 1914-1915; Boletim do Departamento Estadual do Trabalho. São Paulo: Typ. Brasil, Rothschild \& Cia., n. 15, p. 298, anno IV, $2^{2}$ trim. 1915; Im migrantes entrados no Estado de Săo Paulo: 1827 a 1915 . In: Boletim do Departamento Estadual do Trabalho. São Paulo: Typ. Brasil, Rothschild \& Cia., n. 19, p. 183-185, anno V, $2^{2}$ trim. 1916; Boletim do Departamento Estadual do Trabalho. São Paulo: Typographia Brasil, Rothschild \& Cia., n. 34 e 35, p. 7, anno IX, $1^{2}$ e $2^{2}$ trim. 1920; Estatistica dos Imigrantes Entrados no Estado de São Paulo. In: Boletim do Departamento Estadual do Trabalho. São Paulo: Typographia Brasil, Rothschild \& Cia., n. 38 e 39, p. 68-86, anno X, $1^{2}$ e $2^{2}$ trim. 1921; Boletim do Departamento Estadual do Trabalho. São Paulo: Typographia Brasil, Rothschild \& Cia., n. 53, p. 443-448, anno XIV, $4^{2}$ trim. 1924; Immigrantes entrados nos portos do Brasil, de 1908 a 1924. In: Boletim do Departamento Estadual do Trabalho. Säo Paulo: Typographia Brasil, Rothschild \& Cia., n. 56, p. 372-373, anno XV, 3 trim. 1925; Immigrantes entrados no Brasil no periodo de 1884 a 19.39. In: Revista de Imigração e Colonizaçăo. Rio de Janeiro, ano 1, n. 4, outubro de 1940.

4 Cf. TRENTO, Angelo. Là Dov'e la Raccolta del Caffe (L'Emigrazione Italiana in Brasile, 1875-1940), Padova, Antenore, 1984, p. 76. 
MARTINS, José de Souza. A imigração espanhola para o Brasil e a formação da força-de-trabalho na economia cafeeira: $1880-1930$.

diferentes modos, o imigrante espanhol substituísse o imigrante italiano - o que partia e o que não chegava.

Se a imigração espanhola ocorreu, em grande parte, para ocupar, na expansão do café, o lugar até então preenchido pela imigração italiana, é preciso lembrar que a parcela mais substantiva da imigração italiana possibilitara a substituição da força-de-trabalho escrava, em conseqüência da crise da economia escravista, da abolição da escravidão negra, em 1888, e em conseqüência da grande expansão da economia cafeeira: a área cultivada do Estado de São Paulo cresceu quase seis vezes entre 1890 e 1925 , passando de 510 mil hectares para quase três milhões de hectares 5 .

Quando do principal fluxo da imigração italiana, a questão do trabalho livre era uma questão relativamente aberta: ainda havia quem discutisse se o imigrante deveria ser colono do fazendeiro ou se deveria ser um pequeno proprietário ${ }^{6}$. As novas relações de trabalho, que ficariam conhecidas como colonato, estavam emergindo como resultado de diferentes experimentos em torno do regime de parceria e do trabalho por empreitada ${ }^{7}$. Nesse contexto, as reaçóes do imigrante às formas assumidas pela exploração do trabalho, mesmo dispersas e desarticuladas, tiveram um papel muito grande na definição das relaçóes de trabalho. Sobretudo, o tiveram na demolição das concepções escravistas que se escondiam por trás da dominação pessoal do fazendeiro e por trás do endividamento do trabalhador, que eram formas de subjugar o seu trabalho. $\mathrm{O}$ imigrante italiano esteve, portanto diretamente inserido nos dilemas criados pela substituição do trabalho escravo.

Ao mesmo tempo, ele chegou num momento da história brasileira em que se não buscava apenas a forma social de substituição do escravo; chegou num momento em que se abriam oportunidades econômicas, com a liberação de capitais decorrentes do fim do tráfico negreiro, a partir de 1850 , e, sobretudo, com o fim progressivo da escravidão a partir de então. É importante considerar que os anos noventa, do século passado, foram, principalmente em São Paulo, os anos de uma grande diversificação econômica: a criação de bancos, indústrias e

5 Cf. Boletim do Departamento Estadual do Trabalho. Sảo Paulo: Typographia Brasil, Rothschild \& Cia., n. 59-60-61, anno XVI, $2^{2}-3^{2}$ e $4^{2}$ trim. 1927-1928.

6 Cf. COUTY, Louis. L'Esclavage ao Brésil. Paris: Librairie de Guillaumin et Cie., 1881, p. 37; COUTY, Louis. Étude de Biologie Industrielle sur le café. Rio de Janeiro: Imprimerie du "Messager du brésil", 1883, p. 47 e 147.

7 Cf. COSTA, Emilia Viotti đa. Da Senzala à Colônia. São Paulo: Difusẫo Européia do Livro, 1966, passim. 
a grande expansão do café para o oeste. No que diz respeito à atração de mão-de-obra estrangeira, esse foi um momento marcado pela necessidade de provar que, no Brasil, o imigrante não seria escravo, que teria oportunidade de enriquecer, tornar-se proprietário da sua própria terra. Os dados acabariam provando que, de fato, isso não ocorreria em escala apreciável até a crise de 1929. Porém, se a economia agrícola esteve razoavelmente fechada à transformação do imigrante em proprietário de terra, justamente porque era necessário transformá-lo em mão-de-obra à disposição dos fazendeiros, o mesmo não se deu na indústria e no comércio. Esses setores da economia apresentaram-se com uma espécie de território livre, que foi claramente ocupado pelo imigrante e, predominantemente, pelo imigrante italiano. O que não quer dizer, evidentemente, que os grandes fazendeiros tenham se mantido fechados na velha economia de exportação. Na mesma década de noventa, enquanto imigrantes italianos e alemães começavam a montar indústrias na região de São Paulo, os fazendeiros passavam a organizar grandes bancos, que acabariam, de alguma forma, tendo o controle do conjunto da economia ${ }^{8}$.

A grande diferença entre a imigração espanhola e a imigração italiana está em que esta última imigração estava estratificada em classes sociais: havia camponeses sem terra, operários, comerciantes, capitalistas, artesãos, além de intelectuais. A imigração espanhola, ao contrário, foi predominantemente de camponeses. Mesmo os não camponeses, que em certa proporção também imigraram para o Brasil, foram os que mais reemigraram.

A imigração espanhola cresceu acentuadamente quando a imigração italiana subvencionada foi dificultada e quando uma proporção muito alta de italianos começou a deixar São Paulo, entre o fim do século XIX e o começo do século $\mathrm{XX}$, na maioria dos casos, para retornar à Itália ou para reemigrar a outros países. Nesse período, os números de saída de imigrantes italianos superaram os números de entrada. É justamente o período da primeira grande crise do cafe ${ }^{9}$. Como se verá, mais adiante, a imigração espanhola não era diversificada como a ialiana. Não há notícias de grandes capitalistas espanhóis em São Paulo nessa

8 Cf. MARTINS, José de Souza. "Empresários e trabalhadores de origem italiana no desenvolvimento industrial brasileiro entre 1880 e 1914: o caso de São Paulon. In: Dados - Revista de Ciências Sociais, v. 24, n. 2, 1981, p. 237-263.

9 Cf. HALL, Michael M.. Immigration and the Early Sáo Paulo Working Class, s/d, mímeo, p. 7 e 21; Salvio de Almeida Azevedo, Imigraçăo e Colonização no Estado de Săo Paulo. In: Revista do Arquivo Municipal, São Paulo, Dep. de Cultura, v. LXXV, p. 121, abril de 1941. 
MARTINS, José de Souza. A imigração espanhola para o Brasil e a formação da força-de-trabalho na economia cafeeira: $1880-1930$.

época. Em 1904, um jornal espanhol editado em São Paulo, falando dos imigrantes espanhóis, dizia que "o pouco que ganham não lhes chega para mal alimentar-se. Quem se atreverá a negar que a colônia espanhola do Estado de São Paulo é a mais pobre de todas e que se acha composta, na sua maioria, de humildes trabalhadores braçais? (...) Com quantos capitalistas, comerciantes, industriais, etc., etc., conta a colônia?"10.

$\mathrm{Na}$ sua maioria, os imigrantes espanhóis eram camponeses que chegaram ao Brasil com a família, imigrando em definitivo, indo diretamente para o interior, para as fazendas, na maioria realmente pobres, cuja viagem fora subvencionada pelo governo brasileiro. Além disso, em maior proporção foram para as zonas novas, onde as terras eram de menor qualidade ou menos férteis do que nas zonas mais antigas, as do chamado "oeste velho". E eram menores as oportunidades de ascensão, do café. Em outros termos, o imigrante espanhol chegou ao Brasil numa época de poucas oportunidades. Quando o imigrante italiano chegara, o futuro do imigrante era definido por uma perpectiva camponesa e por uma relação de trabalho que, em grande parte, era uma variaçăo das condições de vida camponesa. O colonato estava no seu início. No surto da imigração espanhola, o colonato, já está modificado pela ação e pressão do próprio imigrante italiano e, mesmo, do governo italiano. Uma das principais modificações nas relações de trabalho fora a da ampliação do pagamento em dinheiro e a do acerto mensal com o trabalhador, em vez do acerto anual. A perspectiva do imigrante, nesse outro momento, está, pois, mais próxima do trabalho assalariado, resul tante da lenta desagregação do colonato. $O$ pagamento em dinheiro era, porém, um ardil que, em termos reais, empobrecia o imigrante ainda mais. Um caso ilustrativo é noticiado por um jornal de língua espanhola, em 1908: um colono espanhol, trabalhando com a mulher e três filhos, numa fazenda da região da ferrovia Paulista, ao fim de um mês recebera Rs. $24 \$ 000$, insuficientes para a sobrevivência da família. No típico colonato, ao menos, o trabalhador podia subsistir com o produto da horta e da agricultura, com o intercalar de alimentos. Claramente, os imigrantes espanhóis desse período estão entre os mais pobres e os de menor mobilidade social.

A pouca diversidade da população espanhola no Brasil é revelada não só pelo escasso número de espanhóis proprietários de terra em Săo Paulo: na 
R. Histórla, Sấo Paulo, n. 121, p. 5-26, ago/dez. 1989.

estatística de $1904 / 1905$, apenas $415^{11}$; como também pelos números do censo de 1920. Em todo o Brasil havia 267 estabelecimentos industriais pertencentes individualmente a espanhóis, dos quais 128 localizados em São Paulo. Em média, essas indústrias tinham menos de 7 operários. Na mesma ocasião, os italianos tinham 2119 indústrias desse tipo, igualmente pequenas, das quais $68 \%$ estavam em São Paulo ${ }^{12}$. Entretanto, não há registro de indústrias grandes pertencentes

11 Cf. Secretaria da Agricultura, Commercio e Obras Públicas do Estado de São Paulo, Estatistica Agricola e Zootechnica - Anno Agricola de 1904-1905. 4 vols. São Paulo: Typ. Brasil, 1908. Um autor, questionando, sem maior cuidado, os dados desse levantamento, argumenta que "há toda probabilidade de as cifras do censo de 1905 terem subestimado o número de pequenos proprietários". O motivo seria que "muitos sitiantes e donos de minifúndios náo registraram suas propriedades ou posses (sic) durante esse perfodon. Cf. Maurício A. Font, Padrôes de ação coletiva dos plantadores paulistas de café: 1932-1933, in Fernando Henrique Cardoso et alll (orgs.). Economia e Movimentos Sociais na América Latina. S. Paulo: Brasiliense, p. 220-222, 1985. (Na edição mal cuidada desse livro, há omissão das fontes e referências bibliográficas de praxe, inclusive daquelas apontadas abreviadamente no corpo do texto, o que dificulta a ampliação do comentário que aqui faço). $\mathrm{O}$ argumento desse autor é inteiramente desprovido de sentido e mostra completo desconhecimento dos critérios usados no levantamento estatístico de 1904-1905. Tais critérios foram estabelecidos, com toda a clareza, pelo Decreto $\mathrm{n}^{2}$ 1.323, de 23 de outubro de 1905 (Approva as instruções para o levantamento da estatística agrícola e zootechnica do Estado de São Paulo", in Diario Official, São Paulo, anno 15, n. 236 , pp. 2.539-2.542, 26 de outubro de 1905). Ao contrário do que ele supõe, o levantamento náo foi feito com base em registros fiscais: "Para preenchimento dos mapas, deverão os auxiliares dirigir-se pessoalmente a cada proprietário ou a quem suas vezes possa fazer, solicitando com toda a urbanidade as informações precisas para por si mesmos preencherem os mapas. No caso de recusa do proprietário ou quem por ele possa responder não deverá o auxiliar insistir, cumprindo-lhe, porém, preencher os mapas com as informaçōes que procurará obter dos vizinhos ou conhecidos do recusanten (Ibidem, p. 2.540). Cada uma das cinco zonas em que foi dividido o Estado de Săo Paulo, para realizaçăo desse levantamento, teria um delegado para distribuir o trabalho e rever os mapas. Cada municipio teria um auxiliar que faria o trabalho de campo. Os municipios poderiam ser divididos em secções, cabendo, entăo, a cada uma um auxiliar. $O$ levantamento deveria ser feito até o dia 31 de janeiro de 1906: três meses de trabalho, portanto. Trata-se, pois, de levantamento de campo, cujos dados resultam de pesquisa direta, e não de aproveitamento de registros fiscais viciosos. O viés qũe possa ter havido nessa pesquisa diz respeito, fundamentalmente, à recusa do informante em ceder os dados e à impossibilidade de obtê-los através dos vizinhos. De qualquer modo, tal viés se manifestaria nas informações agrícolas e zootécnicas e não no número de propriedades, pois estas teriam sido forçosamente identificadas no campo.

12 Cf. Ministerio da Agricultura, Industria e Commercio-Directoria Geral de Estatistica, Recenseamento do Brazil Realizado em 1 de Setembro de 1920. Rio de Janeiro: Typ. da Estatística, v. V, $1^{\circ}$ parte, p. LXIII e LXI, 1927. No mesmo ano de 1920, os espanhóis de São Paulo tinham 3.530 estabelecimentos agricolas e os do Brasil tinham 4.725 estabelecimentos. Cf. Boletim do Departamento Estadual do Trabalho. São Paulo: Typographia Brasil, Rothschild \& Cia., n. 46 e 47, p. 29 ss, anno X11I, $1^{\circ}$ e $2^{2}$ trim. 1923.

$$
-11-
$$


MARTINS, José de Souza. A imigração espanhola para o Brasil e a formação da força-de-trabalho na economia cafeeira: $1880-1930$.

a espanhóis, embora, pelo menos a partir de 1890 , existam muitas informações sobre bancos e indústrias grandes de imigrantes italianos. A imigração espanhola foi, portanto, caracteristicamente imigração de mão-de-obra, pouco divesificada e pouco qualificada. Não só o imigrante chegou numa época de poucas oportunidades, como ele próprio era dos menos preparados para aproveitar as oportunidades, se elas existissem. Vale a pena, ainda que de passagem, quanto a esse aspecto, sugerir uma comparação entre a imigração japonesa e a imigração espanhola. O grande surto imigratório de ambos os grupos se dá aproximadamente na mesma época, a primeira década deste século. Ambos imigraram predominantemente em familia, com baixa porcentagem de imigrantes avulsos. Ambos foram predominantemente encaminhados para 0 interior, para as regióes cafeeiras e, particularmente, para as zonas novas. Ambos, quando se tornaram proprietários de terra, tinham as menores áreas médias por estabelecimento rural. $O$ japonês, no entanto, enriqueceu relativamente depressa e manteve uma identidade cultural que o espanhol imigrante não conseguiu manter. Este foi, provavelmente, com o português, o imigrante mais facilmente assimilado, coisa que não ocorreu com o italiano na mesma intensidade. $O$ espanhol desapareceu na sociedade brasileira praticamente sem deixar sinal. Nem mesmo ficou a memória dessa diferença, que existiu um dia e durante um certo tempo.

Também, no que se refere às fontes para o estudo da imigração, há diferenças importantes entre a imigração espanhola e a imigração italiana. Há registro de que, no período de que trato, existiram, ao menos, quinze periódicos em língua espanhola publicados em São Paulo ${ }^{13}$. Deles, praticamente nada mais resta. Encontrei três jornais, do começo do século, dos quais, somados, não há mais do que dez exemplares nos arquivos e bibliotecas da capital. Năo há estudos publicados sobre a imigração espanhola nesse período. Também não há relatórios, cronicas de viagem de autoridades espanholas, escritores, jornalistas, missionários, como há em abundancia em relação a outros grupos nacionais, particularmente o italiano, ricos em informações sobre as condições de vida dos imigrantes. Mesmo os jornais de língua espanhola trazem muito pouca informaçăo sobre o imigrante espanhol no Brasil. "El Diario Espanol", por exemplo, limita-se a reproduzir e publicar notícias de acontecimentos ocorridos

13 Cf. NOBRE, Freitas. História da Imprensa de Säo Paulo. Săo Paulo: Ediçőes Leia, 1950, passim; CAMARGO, Ana Maria de Almeida. Hemeroteca Júlio Mesquita - Catálogo Cronológico. Sło Paulo: Instituto Histórico e Geográfico de Săo Paulo, 1975. 
na Espanha. É possível que os jornais anarquistas tivessem mais informações locais e a respeito das condições de vida do imigrante. Mas um deles, que pude consultar, é particularmente pobre na descrição das situações de conflito envolvendo trabalhadores rurais e fazendeiros. As poucas informações de jornais, a respeito, indicam que as autoridades consulares espanholas tinham pouco interesse pelos espanhóis no Brasil ${ }^{14}$. O que pode ser indício de que a imigração espanhola para este país não se situava em nenhum projeto político ou económico, diversamente do que ocorria com a Itália, que sempre teve, particularmente no período fascista, pretensões de fazer da população italiana no Brasil uma verdadeira colónia econômica e política. Mesmo antes do fascismo, os italianos fizeram muitas pressões para transformar as relações de trabalho nas fazendas de café em relações monetárias, para melhorar a remessa de dinheiro a seu país, por parte dos imigrantes italianos, e para criar um mercado de produtos italianos no Brasil. Náo encontrei nenhum sinal de que algo parecido tenha em algum momento ocorrido com o governo espanhol.

\section{Características da imigração espanhola}

O Recenseamento de 1920 indicou que havia no Brasil 1.565.961 estrangeiros. Desses, 558.405 eram italianos, 433.577 eram portugueses e 219.142 eram espanhóis. ${ }^{15}$ A distribuição desses imigrantes pelo território brasileiro sugere que havia diversidade de condições sociais no interior de cada um dos grupos nacionais. Estavam no Estado de São Paulo 78,2\% dos espanhóis, $71,4 \%$ dos italianos e $53 \%$ do total de estrangeiros. Já os portugueses estavam, na maioria (39,7\%), no então Distrito Federal (Rio de Janeiro) e pouco menos em São Paulo (38,6\%). Na capital de São Paulo, estavam $24,7 \%$ dos estrangeiros do Estado, $14,5 \%$ dos espanhóis, $23 \%$ dos italianos e $38,7 \%$ dos portugueses. No

14 Cf. "Entre amigos", in El Grito del Pueblo (defensor de los intereses del proletariado), Săo Paulo (Brasil), n. 2, p. 2-3, ấo I, 20 de Agosto de 1899. Sobre as reaçoes à indicaçấo de um consul espanhol em Ribeiráo Preto (SP), cf. La Voz de España (organo de la Colonia Espariola), S. Pablo (Brasil), n. 96, p. 1, jueves, affo III, 3 de Abril de 1902.

15 Cf. Ministerio da Agricultura, Industria e Commercio -Directoria Geral de estatistica, Recenseamento do Brazil Realizado em 1 de Setembro de 1920. Rio de Janeiro: Typ. da Estatistica, v. IV, 1' parte, p. 312-317,1926. 
MARTINS, José de Souza. A imigração espanhola para o Brasil e a formação da força-de-trabalho na economia cafeeira: $1880-1930$.

conjunto dos outros Estados, porém, excluído o de São Paulo, viviam nas capitais $46 \%$ dos estrangeiros, $60,2 \%$ dos espanhóis, $24,1 \%$ dos italianos, $79,6 \%$ dos portugueses. Se, no conjunto do país, os italianos, na maior parte, foram para o interior, o mesmo não ocorreu com o imigrante espanhol: em São Paulo ele foi para o interior e, de modo geral, nos outros Estados ficou nas capitais ${ }^{16}$.

Não se tem muitas informações sobre o tipo de trabalho em que se engajou o espanhol que ficou nas cidades. Penso, aliás, que esse tema deveria ser objeto de um estudo à parte. Entretanto, constatei que os imigrantes espanhóis, que ficaram na cidade de Săo Paulo, habitavam de preferência os bairros da Moóca e do Brás, dois típicos bairros operários do começo deste século. No Brás, aliás, localizaram-se de preferência nas ruas onde já haviam se localizado, em anos anteriores, os imigrantes italianos, nos cortiços da região ${ }^{17}$. As estatísticas de acidentes de trabalho ocorridos na cidade de São Paulo, em diferentes anos das duas primeiras décadas do século, indicam que é proporcionalmente alta a incidência de acidentes entre trabalhadores espanhóis nas profissões menos qualificadas, como é o caso dos pedreiros, ajudantes de pedreiros, cocheiros, condutores de bonde, operários, trabalhadores braçais ${ }^{18}$, o que, provavelmente, indica, também, maior concentração de espanhóis nessas ocupações. É possível que em outros Estados, porém, o imigrante espanhol tenha sido, sobretudo, o

16 Ibidem, p. 312-317.

17 Cf. PENTEADO, Jacob. Belenzinho 1910 (retrato de uma época). Săo Paulo: Livraria Martins, p. 57 e 228, 1962; DIAS, Everardo. História das Lutas Sociais no Brasil. São Paulo: Edaglit, p. 42-43, 1962. Um belo romance social sobre as condições de vida e os conflitos entre imigrantes italianos e espanhois, nos bairros do Brás e da Moóca, na cidade de S. Paulo, entre os anos vinte e trinta, é o de Paulo Lício Rizzo, Pedro Maneta, publicado no ińfío dos anos quarenta. Esse autor, quando ainda seminarista do Seminário Presbiteriano de Campinas, fora encarregado de uma congregação no bairro da Mobca. Na convivência com a populaçăo local, recolheu os materiais de seu romance. Faleceu, em 1957, quando era pastor, da Igreja Presbiteriana "Filadélfia", de São Caetano do Sul (SP). Deixou diversos livros inéditos, sobre os cortiços dessa área e dessa época, há a novela, fina e terna, de Afonso Schmidt, Mirita e o Ladräo.

18 Das vitimas de acidentes de trabalho ocorridos na cidade de São Paulo, em 1913, num total de 1.617. 156 eram espanholas. Calculando a porcentagem de acidentados espanhois sobre a soma de acidentados de cada profissão, os espanhóis superam sua própria proporção, sobre o total de acidentados, nas seguintes profissões: cocheiros, pedreiros, serventes de pedreiro, sapateiros, condutores de bonde, serviços domésticos, trabalhadores (braçais), cozinheiros, padeiros. Cf. Boletim do Departamento Estadual do Trabalho. São Paulo: Typ. Brasil, Rothschild \& Cia., n. 10, p. 199-203, anno III, $1^{2}$ trim. 1914. Em 1914, os acidentes de trabalho que vitimaram espanhóis em proporção acima da média, ocorreram nas seguintes profissões: motoristas, serventes de pedreiro, pedreiros, padeiros, operários, mecânicos, empregados. Cf. Boletim do Departamento Estadual do Trabalho. Sáo Paulo: Typ. Brasil, Rothschild \& Cia., 1915, n. 14, p. 179-206, anno IV, $1^{2}$ trim. 1915. 
comerciante ou artesão, como ocorreu com os portugueses no Rio e em São Paulo, como se pode inferir de sua maior presença nas capitais. $O$ que importa destacar neste trabalho é que 78,1\% dos espanhóis que viviam em São Paulo, em 1920 , estavam nas regiões cafeeiras. Isso quer dizer que $61 \%$ de todos os espanhóis que viviam no Brasil, nesse ano, estavam na região paulista de café. Essa era a situação de $36,5 \%$ dos estrangeiros e de $53,3 \%$ dos italianos ${ }^{19}$.

Desde 1880, mais da metade dos imigrantes italianos foram encaminhados para a província de São Paulo e mais da metade dos espanhóis foram-no desde 1890. Mas, só a partir de 1900 é que a imigração espanhola para São Paulo praticamente chegou aos 3/4 da imigração para o Brasil $^{20}$.

Dentre os imigrantes entrados em São Paulo, entre 1908 e 1939, os espanhóis e os austríacos foram os que apresentaram maior índice de fixação, respectivamente $50,9 \%$ e $51,8 \%$, e em relação aos retornos e à reemigração. Quando se considera o balanço de entradas e saídas no país, e não só em São Paulo, o índice dos espanhóis sobe para $53,6 \%$. Nesse período, no que se refere ao saldo líquido de entradas e saídas, apenas $12,7 \%$ dos italianos permaneceram no Estado e apenas $11,5 \%$ dos alemães ${ }^{21}$. Tudo indica que a menor fixação do imigrante e sua maior mobilidade estavam diferentemente relacionados com a característica de imigração do respectivo grupo nacional. Maior proporção de imigrantes avulsos, como era o caso dos italianos nesse período, tendia a aparecer associada a maior porcentagem de saídas sobre as entradas. Maior proporção de imigração familiar, como era o caso dos espanhóis e dos japoneses, tendia a aparecer associada a maior fixação. Dos espanhóis, $18,4 \%$ eram avulsos e dos

19 Para chegar a esses resultados, fiz uma tabulaçăo especial dos dados do Censo de 1920 (Cf. Ministério da Agricultura, Industria e Commercio - Directoria Geral de Estatistica, Recenseamento do Brazil realizado em 1 de Setembro de 1920, v. IV, $1^{\circ}$ parte, p. 818-867, com base na distribuiçăo municipal das plantaçōes de café, de 1918 a 1928. (Cf. Directoria da Agricultura Industria e Commercio. O Cafe, Estatística de Producçäo e Commercio-1928. Såo Paulo: Escolas Profissionais do Lycev Coraçâo de Jesus, 1929, passim).

20 Cf. Estatística dos immigrantes entrados no Estado de São Paulo, 1827 a 1920. In : Boletim do Departamento Estadual do Trabalho. Safo Paulo: Typographia Brasil, Rothschild \& Cia., n. 38 e 39, p. 68-86, anno X, $1^{a}$ e $2^{\circ}$ trim. 1921.

21 Cf. Movimento de passageiros pelo porto de Santos no período de 1908 a 1939. In: Boletim do Serviço de Imigração e Colonização. Săo Paulo: Secretaria da Agricultura, Indústria e Comércio, n. 3, p. 45-76, março de 1941. 
MARTINS, José de Souza. A imigraçăo espanhola para o Brasil e a formaçăo da força-de-trabalho na economia cafeeira: $\mathbf{1 8 8 0 - 1 9 3 0 .}$

japoneses apenas $5,1 \%$, enquanto que essa proporção subia para $42,3 \%$ no caso dos italianos 22 .

Um outro fator de fixação do imigrante foi a imigração subvencionada. A chamada imigração espontanea, do imigrante que custeava sua própria viagem, tendia a afastar o imigrante da agricultura e, consequentemente, dos mecanismos de coerção e da dominação pessoal que marcaram as relações de trabalho nas fazendas de café. Com isso, o imigrante ganhava maior liberdade de locomoção e de escolha do trabalho. A imigração subvencionada, ao contrário, submetia 0 imigrante, desde o começo, desde o embarque, aos critérios e interesses do governo e, em seguida, dos fazendeiros. De 1851 a 1909, o governo imperial e, depois, o governo federal promoveram a imigração subvencionada. A partir de 1881 , o governo de São Paulo, movido pelos interesses dos fazendeiros de café, também aplicou grandes recursos na imigração estrangeira, ate 1927, pouco antes da grande crise de $1929^{23}$. É verdade que o imigrante com viagem paga pelo governo nacional teve, em várias ocasióes, oportunidade de ser encaminhado aos núcleos coloniais oficiais, na condição de pequeno proprietário. Mas, a grande massa de imigrantes subvencionados que se dirigiu a São Paulo teve sua viagem paga pelo governo paulista. Nesse caso, o imigrante praticamente não tinha liberdade de decidir para onde ir e o que fazer. Desembarcado no porto de Santos, em poucas horas o imigrante era conduzido à Hospedaria dos Imigrantes, na cidade de São Paulo. Al permanecia, geralmente, três dias (no máximo oito), sendo em seguida embarcado em trem especial para as regiões do interior onde houvesse maior demanda de força de trabalho. O governo mantinha, desde 1911, um serviço de avaliaçáo do mercado de trabalho, que lhe garantia informação atualizada e permanente sobre a demanda de mão-de-obra, tipo de trabalho, salário ou modalidade de pagamento do trabalho, etc. nas diferentes regióes. Nos livros de registros da Hospedaria dos Imigrantes, é possível, com alguma freqüéncia, acompanhar a trajetória de uma famflia de colonos, praticamente dia a dia, desde a sua aldeia de origem, na Espanha, até a fazenda de café a que fora especificamente destinada no interior de São Paulo.

$\mathrm{Na}$ fazenda, o imigrante entrava numa relação de dívida com o fazendeiro, motivada por antecipaçóes e fornecimentos de alimentos e meios de subsistência, que o prendiam a ele por vários anos. Era, na verdade, uma forma de evitar a mobilidade do imigrante e baratear a força de trabalho. Num caso já citado,

22 Cf. Boletim da Directoria de Terras, Colonizaçäo e Immigraçäo. São Paulo: Secretaria da Agricultura, Indústria e Commercio, n. 1, p. 61, anno I, outubro de 1937.

23 Cr. CARVALHO, Péricles de Mello. A legislaçăo imigratória do Brasil e sua evolução. In: Revista de Imigração e Colonização, Rio de Janeiro, Conselho de Imigraçăo e Colonizaçăo, n. 4, p. 719-736, ano I, outubro de 1940 ; cf., também, TRENTO, Angelo. Ob. cit., p. 22-40. 
ocorrido em 1908 com um imigrante espanhol e sua família, que, ganhando Rs. $24 \$ 000$ por mês não conseguia sobreviver; ao comunicar ao fazendeiro que pretendia deixar a fazenda, o patrão enfrentou-o de chicote na mão. Tendo fugido para dar parte ao representante consular espanhol, sua família foi sequestrada pelo fazendeiro como garantia de uma multa de Rs. $200 \$ 000$ pelo abandono do trabalho ${ }^{24}$.

Em 1902, como já mencionei, o governo italiano proibiu a imigração subvencionada para o Brasil, fato que estimulou a imigração espanhola. Mas, o governo espanhol, ao que parece em 1911, tomou idêntica medida, procurando reprimir a emigração de camponeses pobres. Na época, na Espanha, os emigrantes eram classificados em dois grupos: o dos que retornavam com dinheiro, enriquecidos, caso dos emigrantes de algumas regióes do norte, e dos camponeses pobres, como os de Andaluzia, que emigravam definitivamente para fugir da miséria ${ }^{25}$.

Alguns dados não sistemáticos mostram que o imigrante espanhol que chegou a São Paulo foi, principalmente, o subvencionado. Dos que entraram em São Paulo, em 1911, 71,8\% eram subvencionados, enquanto que o eram apenas $37 \%$ dos italianos e $24 \%$ dos portugueses, sobre um total de $39,3 \%$ de subvencionados no conjunto dos imigrantes. Em 1912, os subvencionados eram: espanhóis, 74,2\%; italianos, $33,8 \%{ }^{26}$.

Apesar da decisão do governo espanhol contra a emigração subvencionada para o Brasil, a imigração subvencionada de espanhóis continuou a ocorrer: procedia da Argentina e do Uruguai e era constituída por espanhóis que

24 Cf. Por las haciendas: bandidaje en acción, in La Voz de españa (órgano de la colonia española), São Paulo (Brasil), ano IX, n. 406, p. 2, 19 de Marzo de 1908. Sobre os procedimentos adotados pela agência oficial na chegada do imigrante, cf. A Immigraçäo $e$ as Condições do Trabalho em Säo Paulo. Secretaria da Agricultura, Commercio e Obras Publicas - Departamento Estadual do Trabalho. Săo Paulo:Typographia Brasil, Rothschild \& Cia., 1915.

25 Cf. POSADA, Adolpho. Politica da emigração. In: Boletim do Departamento Estadual do Trabalho. São Paulo: Typ. Brasil, de Rothschild \& Cia., n. 8 e 9, p. 389-390, anno II, $3^{\circ}$ e $4^{\circ}$ trim. 1913-1914.

26 Cf. Boletim do Departamento Estadual do Trabalho. São Paulo: Typ. Brasil, Rothschild \& Cia., n. 1 e 2, p. 189 ss, anno I, 1912; Boletim do Departamento Estadual do Trabalho. São Paulo: Typ. Brasil, Rothschild \& Cia., n. 5, p. 719 ss, anno I, $4^{\mathfrak{Q}}$ trim. 1912. 
MARTTNS, José de Souza. A imigração espanhola para o Brasil e a formação da força-de-trabalho na economia cafeeira: $1880-1930$.

reemigravam ${ }^{27}$. Dos espanhóis que entraram no porto de Santos em 1916, apenas $30,2 \%$ procediam da Espanha. Entretanto, dos espanhóis imigrados nesse ano, $77,2 \%$ eram subvencionados, o que quer dizer que também uma parte dos que vinham da Espanha tiveram sua passagem paga pelo governo de São Paulo, pois haviam entrado em Santos 7.409 espanhóis, dos quais procediam da Espanha 2.236 e entraram na Hospedaria $5.721^{28}$.

A circulação de imigrantes espanhóis, entrando ou saindo do Brasil, pelo Uruguai ou pela Argentina, foi numericamente importante. No período entre 1908 e $1926^{29}, 38.648$ espanhóis entrados no Brasil vieram da Argentina e do Uruguai $(20,1 \%$ dos imigrantes espanhóis da época). O mesmo ocorreu com 33.368 italianos (18,5\% dos imigrantes italianos do período). Em compensação, saíram de São Paulo com destino à Argentina e ao Uruguai, na mesma ocasião, 44.991 espanhóis ( $52 \%$ das saídas desses imigrantes) e 43.488 italianos (28\% dos migrantes dessa nacionalidade). Um fluxo que claramente favorecia aqueles dois parses, particularmente a Argentina. Esse quadro é indicativo das dificuldades para reter e ampliar o contingente de mão-de-obra estrangeira na região paulista. Não por acaso, nessa época, começa-se a falar na possibilidade da migração sazonal de trabalhadores do Nordeste, que pudessem colher café em São Paulo e retornar a seus lugares de origem ${ }^{30}$. Uma solução que implicaria em introduzir mudanças profundas nas relaçôes de trabalho das fazendas

27 Em 1914, entraram em São Paulo 14.903 imigrantes espanhóis e procediam da Espanha apenas 11.402 (76,5\%). Cf. Boletim do Departamento Estadual do Trabalho. São Paulo: Typ. Brasil, Rothschild \& Cia., n. 12 e 13, p. 806-807, anno III, $3^{\circ}$ e $4^{\circ}$ trim. 1914-1915. Em 1915, entraram 4.369 espanhois e desembarcaram apenas 2.607 pessoas procedentes da Espanha $(59,7 \%)$. Cf. Boletim do Departamento Estadual do Trabalho. Sáo Paulo: Typ. Brasil, Rothschild \& Cia., n. 17, p. 733-735, anno IV, $4^{\circ}$ trim. 1915. Em 1916, entraram 7.409 espanhóis, embora procedessem da Espanha apenas 2.236 pessoas $(30,2 \%)$. Cf. Boletim do Departamento Estadual do Trabalho. Săo Paulo: Typ. Brasil, de Rothschild \& Cia., n. 22, p. 209-211, anno VI, $1^{\circ}$ trim. 1917. Em 1917, entraram 9.691 espanhóis, dos quais apenas 1.834 embarcados em portos da Espanha $(18,9 \%)$. Cf. Boletim do Departamento Estadual do Trabalho. São Paulo: Typographia Levi, n. 26, p. 301-303, anno VII, $1^{2}$ trim. 1918. Em 1924, entraram 5.639 espanhóis, dos quais 3.545 embarcados em portos da Espanha (62,9\%). Cf. Boletim do Departamento Estadual do Trabalho. Săo Paulo: Typ. Brasil, Rothschild \& Cia., n. 54 e 55, p. $40-41$ e 204, anno $X V, 1^{\circ}$ e $2^{\circ}$ trim. 1925. Em 1926, desembarcaram 5.180 espanhóis, sendo que 4.117 procediam da Espanha (79,5\%). cf. Boletim do Departamento Estadual do Trabalho. Säo Paulo: Typographia Brasil, Rothschild \& Cia., n. 58, p. 9-12, anno XVI, $1^{2}$ trim. 1927.

28 Cf. Boletim do Departamento Estadual do Trabalho, n. 22, p. 209 ss, anno VI, 1916.

29 Cf. Boletim do Departamento Estadual do Trabalho. Säo Paulo: Typographia Brasil, Rothschild \& Cia., n. 59-60-61, anno XV1, 2 ${ }^{\circ}, 3^{\circ}$ e $4^{\circ}$ trim. 1927, passim.

30 Cf. Boletim do Departamento Estadual do Trabalho. São Paulo: Typ. Brasil, Rothschild \& Cia., n. 23, anno VI, $2^{\circ}$ trim. 1917. 
cafeeiras, mas que só ocorreria em grande escala muito tempo depois, nos anos sessenta deste século.

Na realidade, a reemigração, a saída de imigrantes espanhóis e italianos, atingia pouco a lavoura. O perfil do imigrante desse período, de 1908 a 1926, é a esse respeito muito claro. Dos 192.206 espanhóis entrados em São Paulo, apenas $17,3 \%$ eram indivíduos avulsos, sem família, (comparados com $41,6 \%$ dos 180.061 italianos que imigraram na mesma época). Eram agricultores $81,4 \%$ dos espanhóis e 52,2\% dos italianos. Artistas (artesāos e operários) eram 2,2\% dos espanhóis e $11,4 \%$ dos italianos. Na categoria de "diversos", estavam 16,3\% dos espanhóis e 36,5\% dos italianos. Dos 86.512 espanhóis que sairam, 31,5\% eram agricultores, $0,6 \%$ eram artistas e $67,9 \%$ estavam na categoria de "diversos". Dos 155.230 italianos que reemigraram, as proporções eram respectivamente: $37,7 \%$ agricultores, $2,8 \%$ artistas e $59,6 \%$ "diversos". No conjunto dos imigrantes entrados em São Paulo, 59,4\% eram agricultores e, no conjunto dos que saíram, 74,3\% estavam na categoria de "diversos" ${ }^{31}$.

Alguns dados esparsos, relativos a diferentes anos, sugerem que essas três categorias de imigrantes espanhóis tinham origem regional diversa. Dos que chegaram a Santos em 1916, 58,3\% embarcaram em Gilbratar, no sul, e 28,4\% em Vigo, no norte. Dos chegados em 1917, 65,9\% embarcaram no primeiro porto e 21,6\% no segundo. Em 1924, 64,9\% haviam embarcado em Gilbratar e 8,7\% em Vigo. Para esse ano, porém, há indicação dos portos de destino dos que reemigraram: apenas 2 passageiros foram para Gibraltar; $15,3 \%$ para Vigo, 4,5\% para Almeiria e 3,9\% para Málaga; $58,2 \%$ foram para Buenos Aires e Montevidéu, num total de 3.516 emigrantes. Esses dados parecem indicar que a maioria dos que retornaram para a Espanha, isto é, não-agricultores, procedia do norte daquele pais ${ }^{32}$.

31 Cf. Boletim do Departamento Estadual do Trabalho, anno XVI, n. 59-61.

32 Cf. Boletim do Departamento Estadual do Trabalho. São Paulo: Typographia Levi, 1918, n. 26, p. 303, anno VII, $1^{2}$ trim. 1918; Boletim do Departamento Estadual do Trabalho. n. 22, p. 211, anno VI. Boletim do Departamento Estadual do Trabalho. Sâo Paulo: Typographia Brasil, Rothschild \& Cia., n. 53, p. 40-41, anno XIV, $4^{2}$ trim. 1924. 
MARTINS, José de Souza. A imigração espanhola para o Brasil e a formação da força-de-trabalho na economia cafeeira: $1880-1930$.

\section{O colono e a propriedade da terra}

Em meados do século XIX, quando foi proibido o tráfico negreiro para o Brasil, o café se localizava predominantemente no Vale do Paraíba, com seus núcleos mais importantes na região próxima ao Rio de Janeiro. Foi em seguida se deslocando para a região central da província de São Paulo, através do Vale do Paraíba. Nos anos 80 do século passado, o café avançou para o que seria chamado depois de "oeste velho", em direção às regióes que ficaram conhecidas como Mojiana e Paulista. A partir dos anos de 1910-1920, o café se deslocou em direção ao "oeste novo", às regiões da Araraquarense, da Alta Sorocabana e, finalmente, para Noroeste ${ }^{33}$. O deslocamento espacial do café coincidiu com progressivas mudanças nas relações de trabalho nas fazendas cafeeiras: nesse processo, o trabalho escravo cedeu lugar ao trabalho do colono, predominantemente estrangeiro. Este, por sua vez, foi das relações de parceria agrícola a diferentes formas de colonato.

Na sua fórmula mais geral, o colonato constituiu uma relação de trabalho que procurou preservar aspectos de uma condição camponesa modificada, mediante a produção direta, pelo colono, de uma parte dos seus meios de vida, combinada com a exploração do trabalho pelo fazendeiro. No colonato, o trabalhador se engajava com sua família e não como trabalhador avulso, a não ser para determinadas tarefas complementares do trabalho do colono propriamente dito. Recebia o cafezal formado e seu trabalho consistia em tratá-lo, fazer as carpas necessárias, mantê-lo limpo e colher o café. Recebia um pagamento anual pelo trato do cafezal, por lotes de mil pés de café tratados (um adulto geralmente tratava de dois mil pés de café) e outro pagamento para cada 50 litros de café colhido por sua família. Em 1919, esse pagamento anual em dinheiro correspondia a aproximadamente quatro vezes o dinheiro necessário para a alimentação de uma família operária na cidade de São Paulo durante um mês. Ou seja, todo o rendimento monetário anual do colono correspondia a apenas quatro salários mensais do trabalhador urbano, devendo cobrir o equivalente aos outros oito salários com a produção direta de gêneros de subsistência. Além disso, o colono reparava cercas e caminhos, apagava incêndios e limpava pastos gratuitamente. Tinha, porém, direito de plantar feijão, milho e até arroz nas ruas do cafezal, às vezes em parceria com o fazendeiro,

Cf. MILliet, Sergio. Roteiro do Café e Outros Ensaios. $3^{\text {a }}$ ediçáo. S. Paulo: Depto. de Cultura, 1941, p. 5-72; MONBEIG, Pierre. Pionniers et Planteurs de São Paulo, Paris: Librairie Armand Colin, 1952, p. 147-190. 
cuja colheita em parte consumia e em parte vendia. Além do mais, fora de suas obrigações regulares no cafezal, o colono podia trabalhar como assalariado da própria fazenda ou de outra fazenda vizinha. Podia, também, recorrer ao trabalho assalariado de outro trabalhador como auxílio em tarefas de obrigação de sua família, que não pudesse cumprir. Tinha, ainda, direito à moradia, à horta e a ter um ou dois animais no pasto da fazenda.

Essa fórmula geral variou em função, basicamente, de dois fatores. Um deles foi o modo de plantar, relacionado com a variedade de cafeeiro cultivada. Quando as plantas eram mais próximas umas das outras, como tendeu a ocorrer à medida em que os cafezais se deslocaram para oeste, ficava difícil a agricultura intercalar de alimentos, por causa da sombra. Nesse caso, a tendência foi expulsar a agricultura de alimentos para fora do cafezal, em terras à parte, dentro da fazenda, geralmente impróprias para o cultivo do café. Outro fator, foi o preço e a qualidade das terras. No primeiro caso, a elevação dos preços de terra nas regiōes novas em relação às velhas, em termos relativos, impõs o uso preferencial da terra com a agricultura de exportação, o café, deixando a cultura de alimentos para terras de qualidade inferior. No segundo caso, as terras menos férteis, das regiões mais novas, em relação às terras mais férteis da Mojiana, por exemplo, não recomendavam a cultura intercalar, que prejudicava as raizes do cafeeiro. Esses dois fatores interferiram diretamente na própria estrutura do colonato, cujo modelo clássico permitia conciliar num único processo de trabalho, e no mesmo terreno, a produção direta dos meios de vida e a produção do cafe ${ }^{34}$.

A produção direta dos meios de vida pelo colono, em terras do fazendeiro e terras de café, com a mudança no uso e no custo da terra, fez com que essa produção, aparentemente gratuita e sem custo, passasse a ter um custo regulado pela renda da terra. Quando o café entrara na região da Mojiana, as terras ainda podiam ser obtidas a preços ínfimos. Mais tarde, porém, nas zonas novas, as terras passaram a ser negociadas por grandes empresas imobiliárias, algumas estrangeiras, que extraíam dos novos fazendeiros não só a renda absoluta, equivalente do preço da terra propriamente dito, mas extraíam também a renda diferencial, um sobrepreço, decorrente da maior fertilidade presumível das terras novas em relaçăo às terras velhas (o tempo, porém, demonstraria que as terras velhas da Mojiana eram de melhor qualidade do que as terras novas da Alta

34 Cf. MARTINS, José de Souza. Del esclavo al asalariado en las haciendas de café, 1880-1914. La génesis del trabajador volante, in Nicolas Sánchez-Albornoz (org.), Población y Mano de Obra en America Latina, Madrid: Alianza Editorial, 1985, passim. 
MARTINS, José de Souza. A imigração espanhola para o Brasil e a formação da força-de-trabalho na economia cafeeira: $1880-1930$.

Sorocabana, por exemplo). Uma indicação nesse sentido é que, em 1928, tendo em conta a produtividade dos cafezais (que, de modo geral, havia caído muito em todo o Estado, desde o começo do século) e o preço da terra, as terras das regiōes novas, menos férteis do que as da Mogiana, custassem proporcionalmente mais, embora mais distantes do porto de Santos ${ }^{35}$. Nessas condições, a agricultura intercalar do colono aparecia como um desperdício, como uso anti-econômico de terra que devia ser destinada à produção de café.

A expulsão da agricultura de subsistência de dentro dos cafezais, que marcou especialmente a ocupação das terras do oeste novo, na prática implicou em obrigar o colono a duas jornadas de trabalho - uma no cafezal e outra na roça, já que haviam coincidência de época no trabalho que devia fazer naquele e nesta. Ao que parece, isso exigiu uma redistribuição do trabalho no interior da família, com a incorporação da mulher e de filhos menores ao trabalho da roça, em prejuízo do trabalho doméstico e da horta, envolvendo um trabalhador adicional sem modificações nos ganhos da família do colono.

De modo geral, a imigração espanhola coincidiu com a expansão dos cafezais para o oeste novo, enquanto que a imigração italiana coincidira com a ocupação do oeste velho. Em 1920, dos 133.749 espanhois que viviam nas regiôes cafeeiras, $49,9 \%$ estavam nas zonas novas, enquanto que nessas zonas estavam $31,9 \%$ dos italianos, e $27,2 \%$ dos brasileiros. No oeste velho, viviam $57,4 \%$ dos brasileiros, $66,6 \%$ dos italianos e $48,3 \%$ dos espanhóis. Estes últimos tinham uma presença acima da média na Araraquarense, na Alta Sorocabana e na Noroeste. os italianos estavam acima da média na Mogiana, na Paulista e na Araraquarense $^{36}$. Evidentemente, tanto espanhóis como italianos podiam ser encontrados nas várias regiốes do Estado. $\mathrm{O}$ que faço aqui é apontar tendências e proporções diferenciais na ocupação do espaço pelas populações de diferentes nacionalidades.

Os imigrantes, e também os trabalhadores nacionais, podiam ser encaminhados aos cafezais como colonos ou como trabalhadores avulsos. Colono significava trabalhador residente, com a família, incumbido do trato e da colheita. Cada vez mais, em decorrência do encurtamento do ciclo do café, e isso atingiu particularmente os cafezais das zonas novas, a colheita tinha que ser feita por grande número de pessoas, acima da população residente na fazenda. Com

35 C. Secretaria da Agricultura, Industria e Commercio do Estado de Säo Paulo Directoria de Industria e Commercio, O Café. Estatistica de Produção e Commercio, 1928 , cit., passim.

36 C. Ministerio da Agricultura, Industria e Commercio-Directoria Geral de estatistica, Recenseamento do Brazil. Realizado em 1 de Setembro de 1920, v. IV, $1^{\text {a }}$ parte, p. 818-867. 
isso, aumentava a necessidade de trabalhadores avulsos, colhedores de café, que ganhavam por quantidade de café colhido. $O$ estabelecimento de salários específicos para o trabalho de carpa dos cafezais é indicativo de que também esse trabalho passou a ser feito por trabalhadores avulsos. O que quer dizer, cada vez mais, o regime de colonato não era suficiente para dar conta do ritmo e do conjunto de atividades que compunha o processo de trabalho na produção do café. Além disso, as fazendas precisavam de trabalhadores especificamente assalariados, como era o caso dos camaradas, mensalistas, para outras tarefas, complementares ao trabalho do café ou relacionados com outras culturas dentro da fazenda. Os dados assistemáticos existentes indicam de maneira muito clara que o imigrante espanhol era recrutado, em alta proporção, como colono, coisa que também acontecia com o imigrante italiano não avulso. Para a colheita ou para outros serviços dentro da fazenda, recrutava-se o avulso e nesse sentido enquadrava-se melhor os trabalhadores brasileiros ou de outras nacionalidades, que não o espanhol ou japonês. Mesmo engajados em relação de trabalho idêntica à do italiano, como colonos, os imigrantes que se destinavam às novas regióes lá encontravam pagamentos em dinheiro aparentemente mais altos, como mostram os dados do Departamento Estadual do Trabalho, nas condições de trabalho mais difíceis, embora em cafezais de produtividade ainda relativamente alta. Terra nova queria dizer, também, maior número de carpas do cafezal, maiores dificuldades no trato do café e menos tempo para cuidar da cultura de subsistência.

Mesmo para os colonos espanhóis que foram para as regiōes do oeste velho, as condições eram outras em relação aos tempos de chegada dos primeiros italianos. No conjunto, a produtividade dos cafezais caíra de 15 a $30 \%$ entre 1910/1919 e 1918/1928. Ao mesmo tempo, o preço do café declinara desde o fim do século $\mathrm{XIX}^{37}$. Foram esses dois fatores que levaram muitos imigrantes a deixar o Brasil nesse período.

Os poucos imigrantes espanhóis, que se tornaram proprietários, distribuíram-se aproximadamente nas mesmas proporções dos outros imigrantes

37 Cf. Secretaria da Agricultura, Industria e Commercio do Estado de São Paulo Directoria da Industria e Commercio, O Cafe, Estatistica de Produç̧äo e Commercio, 1928, cit., passim: nas regióes tradicionais, como a Mogiana, a produtividade caiu de 62,64 arrobas por mil para 38,30 . Em regiôes mais novas, como a Noroeste, a queda foi de 53,93 arrobas para 47,09. Entre 1918 e 1927 , o preço do caf $\epsilon$, em mil rés, subiu cerca de $300 \%$. Em compensaçäo, o câmbio caiu a menos da metade. Cf. PESTANA, Paulo R..O Café em Säo Paulo. S. Paulo: Typographia Levi, 1927, p. 23. 
MARTINS, José de Souza. A imigração espanhola para o Brasil e a formação da força-de-trabalho na economia cafeeira: $1880-1930$.

espanhóis pelas diversas regiões do interior do Estado, localizando-se de preferência nas regiōes novas.

Uma estatística agrícola e zootécnica, realizada com critério em $1904 / 1905$, indicou que, das 49.522 propriedades existentes no Estado de São Paulo, apenas 415 pertenciam a espanhóis e 4.766 a italianos. São números muito baixos, se levarmos em conta que a partir de 1880 haviam entrado no Estado de São Paulo mais de 600 mil italianos e mais de 150 mil espanhóis ${ }^{38}$. Já nessa altura, quando a ocupação das terras da Noroeste estava apenas começando, em comparação com os proprietários italianos, a proporção de proprietários espanhóis era maior no oeste novo ${ }^{39}$. Em 1930/1931, o número de propriedades de espanhóis havia subido para 8.930 e o de italianos para 27.376. Dentre as propriedades dos espanhóis, $72,2 \%$ estavam nas zonas novas, enquanto que nessas zonas estavam $53,3 \%$ das propriedades dos italianos ${ }^{40}$. E, se considerarmos que já havia uma ampla proporção de descendentes de italianos que aparecem no censo como brasileiros, então fica confirmado que a presença italiana era majoritária nas zonas velhas, enquanto o espanhol predominava nas zonas novas.

A entrada de empresas capitalistas na exploração da renda fundiária, que caracterizou a ocupação das terras do oeste novo, baseou-se, em parte, no apelo publicitário dirigido ao imigrante. Nos jornais das primeiras décadas deste século, escritos em línguas estrangeiras, encontra-se com certa freqüência a publicidade de terras novas oferecidas em tamanho e preço presumivelmente acessíveis ao imigrante. Em 1915, Lélio Piza \& Irmãos põem à venda as terras da "Fazenda Goaporanga" tomadas aos índios Kaingang, aos quais oferecem 400 alqueires (968 ha), colocados à disposição do Serviço Federal de Colocação de Trabalhadores Nacionais e Proteção aos Índios. Dos 243 lotes dessas terras, localizadas na regiấo do Rio Feio, 128 lotes foram vendidos a imigrantes

38 Cf. Secretaria da Agricultura, Commercio e Obras Públicas do Estado de Săo Paulo, Estatistica Agricola e Zootechnica - Anno Agricola de 1904-1905. Faltam os dados para os municfpios de Moji das Cruzes, Sta Isabel, Tietê, Itu, Apiaf e Iguape. No total de proprietários, essa falta corresponde a $13 \%$ das propriedades. Para o número de imigrantes entrados a partir de 1880 , cf. Boletim do Departamento Estadual do Trabalho. São Paulo: Typ. Brasil, de Rothschild \& Cia., n. 19, p. 183-185, anno V, $2^{2}$ trim. 1916.

39 Cf. Secretaria da Agricultura, Commercio e Obras Públicas do Estado de São Paulo, Estatística Agricola e Zootechnica - Anno Agricola de 1904-1905, cit., passim.

40 Cf. Secretaria da Agricultura, Industria e Commercio, Estatistica Agricola e Zootechnica, 1930-1931. São Paulo: Directoria de Estatistica, Industria e Commercio, p. 22-23, 1932. 
espanhóis, $61 \%$ dos quais tinham menos de 75 ha e $32 \%$ menos de 50 ha $^{41}$. Na verdade, a disseminação da propriedade familiar é um recurso para elevar o preço da terra, cuja medida deixa de ser o cálculo do lucro para ser a própria necessidade de terra do pequeno agricultor.

Os dados de 1930/1931, posteriores à crise de 1929, que atingiu profundamente o café, mostram que os espanhóis proprietários tinham em média 21.5 alqueires ( $52 \mathrm{ha}$ ) de terra, metade da média das propriedades de brasileiros. Em 1933-34, os espanhóis já tinham 14.410 propriedades e os italianos 33.590. Um dos efeitos da crise econômica foi, justamente, a liberação de terras para pequenos agricultores, geralmente imigrantes: $85 \%$ dos espanhóis e $73 \%$ dos italianos proprietários tinham menos de 25 alqueires (60.5 ha) de terras, em média. O café era cultivado, mesmo na crise, em $52 \%$ das propriedades de espanhóis e em 59\% das de italianos, ocupando, respectivamente, $21 \%$ e $17 \%$ da terra de cada propriedade, em média. Parcelas bem menores eram destinadas ao cultivo do milho, do feijão, do arroz, do algodão, da cana, da mandioca e da batata $^{42}$

As oportunidades para os imigrantes espanhóis, e ainda assim apenas uma parcela pequena deles, surgiram apenas quando a crise destroçou a velha economia do café e com ela solapou a base das relações de trabalho do colonato. Como imigrante tardio, o imigrante espanhol que se localizou nas fazendas de café como colono, "escolheu" a relação de trabalho mais crítica, mais próxima da condição camponesa, e mais afastada da realidade dos novos tempos, marcada pela monetarização crescente das relações de trabalho. Evidentemente, ele não tinha alternativa. Vitimado pelo fim das relações de propriedade que se desagregavam na Espanha, ao que tudo indica pelos poucos depoimentos que pude ouvir, veio viver no Brasil o começo do fim do colonato, a crise da longa e penosa transição das relações de trabalho da escravidão para o assalariamento.

41 Cf. Diario Español, n. 2.131, p. 4 e 5, afio XVIII, viernes, 12 de Mayo de 1916; Cf,, também, Mensagem Apresentada ao Exmo. Snr. Dr. Carlos de Campos, em $1^{8}$ de Maio de 1924, pelo Exmo. Snr. Dr. Washington Luis Pereira de Sousa, p. 42-43.

42 C. Secretaria de Estado dos Negocios da Agricultura, Industria e Commercio, Recenseamento Agricola-Zootechnico Realizado em 1934. São Paulo, Ánno Agricola 1933-34, p. 25, 1936. A respeito desse fenômeno, cf. MILlIET, Sergio. O desenvolvimento da pequena propriedade no Estado de São Paulo, in Roteiro do Café e Outros Ensaios, p. 73-116. 
MARTTNS, José de Souza. A imigraçâo espanhola para o Brasil e a formação da força-de-trabalho na economia cafeeira: 1880-1930.

ABSTRACT: Spanish speaking immigrants as compared to the italians faced less opportunities of social mobility. Subventioned by the provincial government, they came to substitute for outgoing italian workers, after 1902. Very few of them achieved their goal of owning small landed properties. Low qualified workers, they came mainly as wage labor for new areas of coffee plantation. Of rural origin, they were assimilated into Brazilian society, leaving few traces of national and group identity. Statistical data is carefully worked through a national and regional perspective, as well as the different stages they faced in the transition to free labor.

UNITERMS: subventioned immigration, peasants, wage labor, transition from slave to free work. 